\title{
Science, Relativism and the New Sociology of Technology: Reply to Russell
}

\section{Trevor Pinch and Wiebe Bijker}

We welcome Stewart Russell's paper, 'The Social Construction of Artefacts: A Response to Pinch and Bijker' ${ }^{1}$ not only because the author fully supports our objective of 'developing an explanation of the content of technology', but also because the points he raises give us an opportunity to comment further upon the exciting developments in this new field of science studies.

Since writing our earlier paper advocating a new sociology of technology, the rapid growth of this field has been most encouraging. Two edited collections of papers have appeared in which the theme of a sociology of the content of technology is developed. ${ }^{2}$ Furthermore, an international Workshop has been held which has brought together proponents of a variety of new approaches in the history and sociology of technology approaches which are in sympathy with many of the proposals outlined in our earlier paper. An edited volume of papers from this workshop will appear later this year. ${ }^{3}$ As one commentator has noted in discussing this Workshop, 'we may look back to it as the place where the social study of technology first became a recognizable field' ${ }^{4}$ One of the most satisfying things about these recent developments is that detailed empirical case studies which attempt to show how the content of technology is socially shaped are at last being carried out. Thus, in a sense, our earlier paper has rapidly been overtaken by events in the field. ${ }^{5}$

Social Studies of Science (SAGE, London, Beverly Hills and New Delhi), Vol. 16 (1986), 347-60. 
In view of the eclectric rather than purist character of the new field, and its rapid growth, it would be myopic to address the issues raised by Russell purely in terms of our own social constructivist approach. Our particular form of analysis is only one of several, and much of the recent work is relevant to the general points which Russell raises. Thus, in our Reply, we will, where appropriate, refer to the wider body of work which has been produced over the last two years.

The object of the new sociology of technology is to explain how technology is socially shaped and, in that this goal is also professed by Russell, we have no serious quarrel with his general approach. Much of his paper concerns an exposition of Marxist ideas - and, in particular, labour process theory - and suggestions for how technology could potentially be understood within such a framework. We much appreciate this contribution, which is certainly far more detailed than that contained in our paper. We feel, however, that it is rather unfair to chastise us for having 'skimmed' over this literature, since our aim was to review empirical studies of technology which treated the content of the technology seriously. Since, as Russell himself admits, the labour process (and other Marxist) work, 'with its as yet limited treatment of technology', does not as yet represent a coherent body of literature which shows how the content of technology is socially shaped, we did not feel that such work merited an extensive review.

Neither do we feel embarrassed that we failed to acknowledge 'more general social analysis and work on other topics'. Of course, our work, like most social science, is informed by particular traditions of social analysis. Also, clearly, the study of other spheres of society can provide insights into technology. However, Russell cannot seriously have expected us to spell out all our analytical assumptions and review all the possible relevant literature in what was meant to be a provocative review/discussion paper. We felt that placing the debate in the context of what is widely acknowledged to be a lively and empirically well-supported tradition of study of a technical culture - the sociology of science - was more than adequate to our task.

This raises perhaps the most serious point of contention between us - the relevance of the work on science. We think that Russell's apparently superficial understanding of the sociology of science has led him to underestimate its potential as a resource for 
understanding technology. We will thus commence by returning to the issue we dealt with previously - the salience of treating science and technology within a common framework. We will then move on to examine other points of disagreement, before closing with one of the most interesting points raised by Russell - the implications of the new sociology of technology for politics and policy.

\section{Science and Technology: Are They Significantly Different?}

In brief, our argument for treating science and technology within the same framework stemmed from three considerations: (1) the unsatisfactory nature of the attempts to demarcate between science and technology; (2) the practical problems encountered by researchers investigating the science/technology relationship, and, in particular, the difficulties of distinguishing the separate contributions made by science and technology to particular innovations; and (3) the concrete demonstration (with examples drawn from our own empirical work on science and technology) that problems and issues raised by the study of science are similar to those raised by the study of technology.

In arguing that the literature in sociology of science was relevant to the study of technology we did not mean to suggest that the similarities between science and technology resided solely in them both being knowledge systems. Our argument was rather that science and technology could both be treated as socially constructed cultures. The work on science treats knowledge as part of a body of practices and methods shared within a cultural framework. Thus, our 'constructivist' approach to science and technology does not, as Russell implies, mean that we treat technology purely as a knowledge system. Indeed our concern with the development of specific technological artefacts, such as the bicycle, should have indicated that we were not talking merely about 'parts of a knowledge system' or 'intellectual commitment to one explanation or other'. Russell seems to have misread the sociology of science literature, since he appears to be under the impression that it concerns matters such as 'how the direction of theory is settled in science', and the part played by 'ideology in theory'. As we mentioned above, in the sociology of science (at least since Kuhn) the study of instrumentation and practices is 
integral with the study of theory.

The parallels between the work on science and that on technology can be made even sharper by considering recent studies of scientific instrumentation. The aim has been to show how different cultural assumptions are embedded within instrumentation and instrumental practices. ${ }^{6}$ In that scientific instruments and the machines of technology share the property of being material artefacts which gain their meaning from the social world, we again can only find encouragement for treating them in equivalent ways. Once it is recognized that the sociology of science conceives of knowledge in an active way - in terms of how that knowledge is rendered and reproduced in practices and in instrumentation - Russell's point about it being unable to deal with purposes and specific social interests evaporates.

Russell seems also to have misunderstood the notion of 'success' as used in the sociology of science. He claims that to talk about the 'success' of an artefact brings with it connotations of consensual acceptance which may be totally inappropriate. He cites the example of factory employees who have no say in the success of a particular technology and may even be disadvantaged by its adoption. However, in the context of science, metaphors such as 'consensus over the facts of the natural world' or the 'success of quantum theory' do not mean that everyone who is affected by the consensus must have taken an equal part in shaping it. The alienated laboratory technician who sets up an experiment in a university laboratory to demonstrate yet another new quantummechanical effect stands in the same relationship to the consensus over quantum theory as the factory employee who has to work with (or be put out of work by) the new technology. Again, we see no difficulty here, provided it is borne in mind that in both science and technology only certain social groups will play a key role in shaping the consensus.

All this, of course, is not to say that there are no differences between science and technology - clearly, there are. Russell draws attention, for instance, to the narrowly defined context in which disputes in science are usually settled, as opposed to the more heterogeneous environment in which technology develops. This is a point we fully endorse - indeed, it was actually made by us in our original paper. However, we take such differences to be a matter of degree, and not as representing any fundamental distinction as to how the two cultures should be approached. Some 
technologies will develop in comparatively homogeneous isolated environments, such as within the confines of an R\&D laboratory; on the other hand, areas of science, such as medical science or health economics, are very diffuse, and their findings will be relevant to, and shaped by, a variety of audiences. ${ }^{7}$ The aim of our integrated approach is to start out by treating the two cultures in an equivalent way, and to abandon this programme only when, in our studies of technology, it no longer pays dividends to use the ideas drawn from science. We cannot expect all ideas drawn from the sociology of science to transfer equally well. Of course, the transfer of ideas between the two contexts is a two-way process. Thus, we envisage that our understanding of science may also benefit from the new work on technology.

\section{The Hard-Case Argument}

The difference between our approach to technology and that of Russell seems to be a matter of emphasis. We emphasize the need to study the internal workings of technology, while Russell puts the stress upon the study of macro-social structure. However, we would claim that our approach is better suited to meet what we call the 'hard-case argument' against the new sociology of technology. There is something particularly compelling about technological artefacts - after all, they 'work'. As Mulkay points out, it is not enough to say that a working television set can be given different interpretations or socially constructed meanings. ${ }^{8}$ What needs to be tackled is the very problem of 'workability' itself. This can be seen to be at the core of much technological determinism - the notion that engineers design and build technologies which in some technical sense can be said to work unproblematically, and which enable the technical performance of different machines and technologies to be monitored, compared and assessed. We would claim that it is strategically important for the new sociology of technology to address this reliance upon the 'purely technical' if it finally wants to lay technological determinism to rest. The way to combat this argument is not to turn to macro-sociological theory, or to speculate about possible alternative technologies, but to carry out micro-studies of how engineers and technologists actually go about deciding whether or not a technology works and how it is to be tested. 
This is a lesson which has been learnt in the sociology of science. Many of the recent advances made by that field have come about because researchers have produced detailed micro-studies of how scientists carry out experiments and reach decisions over what the facts of Nature are. This has enabled the sociology of science to counter, in a most compelling way, the argument that somehow scientists have an unproblematic methodology or epistemological warrant to provide the one true account of Nature - thereby denying the relevance of sociology. Similarly, if we want to pursue a full-blooded sociological approach towards technology, then we would claim that the starting point must be the micro-study of how technologies are tested, and of how engineers make such technical assessments. ${ }^{9}$

\section{Evolutionary Model}

Many of Russell's criticisms concern details of our approach. For instance, he raises objections to our use of an evolutionary model in our description of how the developmental path of an artefact may be traced. Having rejected linear models of technological development, we found it useful to trace several different developmental paths, and to look at this process in terms of variation and selection - especially in relation to the particular problems posed by artefacts for social groups. Russell's main objection here is that such an approach is overly constraining in that it does not consider possible variations which are never manifest. Although there are difficulties with the evolutionary approach, especially when that approach is followed too mechanistically, we do not take this to be a fundamental criticism. ${ }^{10}$ Our evolutionary model can consider totally new departures in technologies, provided there is a social group who define some particular problem which the technology addresses.

We are somewhat perplexed by Russell's comments about our failure to consider the full range of alternatives, because our whole approach is intended to focus attention upon just the sorts of thing he emphasizes - failed technologies and alternative technologies. For example, we treat seriously developments in bicycle technology which are considered by historians writing from the point of view of current bicycle technology to be merely aberrations (for more details, see our original paper). Within the new sociology of 
technology as a whole, the study of alternative technologies is prominent. For example, Michel Callon, who was one of the first scholars to argue the similarities between the study of science and technology, has carried out a detailed study of the attempt to develop the electric vehicle in France as an alternative to internal combustion motor cars. ${ }^{11}$ It is the study of alternatives and failures which is a crucial part of the argument against technological determinism. If a technological artefact can be shown to have more than one developmental path, and if radical departures are possible, then this argues against the view that there is a necessary immanent logic of technical development.

Perhaps the difference here is again one of emphasis. Our programme is empirically orientated, and thus we focus upon alternatives as proposed in historical reality. There is nothing to stop us dreaming up totally new alternatives which the participants in certain circumstances might have thought up themselves. However, we consider this raises more problems than it solves. Even if we as sociologists had the arrogance and technical expertise to point to possibilities which the participants themselves failed to see, explaining why those hypothetical options never took off would raise all sorts of counter-factual difficulties. We think the argument against technological determinism can be made in the most compelling way by considering alternatives which were manifest, and then by attempting to explain why such paths eventually failed.

\section{Social Groups and the Appropriate Unit of Analysis}

Russell raises problems with our use of the notion of 'social groups'. In particular, he criticizes us for failing to emphasize the integration of social groups, and for our failure to locate such groups in a structured and historical context. We are less worried about this latter point, since all forms of sociological explanation in which groups or structures are identified can never be adequate in the sense that all groups and structures are themselves embedded within an endless web of other groups and structures. Spelling out all such contexts is clearly impossible. All that can be attempted is to spell out sufficient context for the purposes at hand. We would claim that, for the development of a technology such as the bicycle, with its heavy participation of consumer 
groups, our analysis in terms of social groups is perfectly adequate. Of course, as we analyze different types of technology, more elaborate concepts may be needed. For instance, one of us (Bijker), in a study of Bakelite technology, has extended the model of social groups into a theory of 'technological frames' in which participants have differing degress of inclusion within different frames. ${ }^{12}$ Also, within the new sociology of technology as a whole, a variety of network and systems approaches is favoured. These models stress the integration of a variety of technical, social, political and economic factors in the shaping of a technology. ${ }^{13}$ Such approaches provide a useful way to address the need for integration which Russell rightly points to as a weakness of the social group approach.

Again we would stress the empirical orientation of our approach, and the crucial role we give to understanding the content of the technology being studied. It is easy when you lose sight of the content of the technology to write volumes on the complex social structure of modern industrial society. Russell and his colleagues in labour process theory need to show us how their elaborate theoretical structures can be used to explain the development of particular technologies. The analysis in terms of social groups may be too simplistic for most technology, but it does at least provide a useful starting point. ${ }^{14}$

Finally, on the topic of the correct unit of social analysis to be used in the study of technology, we would like to point out that a way round the familiar problem of the micro/macro distinction is offered by the new work on technology. ${ }^{15}$ By studying the activities of engineers in laboratories it is possible to understand how society is transformed in the laboratory. This point follows from the notion, particularly prevalent in the actor network and systems approaches to technology, that technological systems and networks integrally contain societal elements. That is to say, rather than picturing macro-society as constraining technological development, we can think of the technological system shaping its own societal environment. Thus, in an important sense, Edison's laboratory activities shaped not only the future development of electric power systems, but also the environment or society of which electric power is a constitutive part. ${ }^{16}$ This treatment of the micro/macro issue offers an alternative to the traditional Marxist approach, with its emphasis on macro-social structure. 


\section{Relativism and its Political Consequences}

Russell puts forward two criticisms of our relativist position. In the first place he claims that we put the emphasis upon form and 'ignore content'. This point can readily be dealt with, as it must stem from a misunderstanding of the nature of our work - and, indeed, of all the work in the sociology of science and technology we draw upon. Such work is characterized by placing the content of the science or technology at the centre of the analysis. Thus, in discussing the development of solar physics or the bicycle, we focus upon analytical objects and problems which the scientists and engineers themselves deal with. For example, our discussion of the development of the bicycle includes a discussion of engineers' problems such as the design problems of increasing the speed of the bicycle and the difficulties raised by the introduction of the new air tyre. Certainly we focus upon form as well as content, but we do not understand Russell's point that we ignore the content of the technology - it is simply not the case.

Russell's second criticism of relativism is potentially more interesting. He points out that if we treat technology as being inseparable from society and politics, then we cannot be relativists merely about material artefacts - we must, to be consistent, be relativists about social and political structures as well. This raises the spectre of political neutrality, and presents particular difficulties for Russell, given his own political commitments. As a way around the problem, he outlines a distinction between methodological and substantive relativism. Sociology of technology could presumably be committed to a methodological relativism, but this need not entail any substantive relativism on matters of political principle. Unfortunately, Russell does not expand upon this interesting distinction. However, we would like to take this opportunity of commenting upon possible political and policy implications of the relativist stance towards technology.

The first point to be made is that if we wish to counter technological determinism and reserve the fullest possible sociological explanation for the development of technology, then we cannot weaken our relativist stance, in which we assume that there are no absolute grounds on which purely technical criteria of technological progress can be based. If there were such grounds available, then the need for a full-blooded sociological approach is 
clearly in question. One could always opt for a compromise position in which societal influences are seen as sometimes winning out over the purely technical factors, but such a position would require us to spell out what these criteria were, and under what circumstances they could be relaxed. ${ }^{17}$ We prefer to opt for the strongest position, and to push it until we meet case studies which just cannot be treated within this stance.

However, an approach in which technical factors are treated in a relativist way does not necessarily lead to moral and political relativism - or even, for that matter, to ontological relativism. The point can be made by giving examples of scholars who profess the type of relativism outlined above (often known as 'cognitive relativism'), but who have no difficulties in rejecting relativism in other spheres. For example, relativist writers in the sociology of science, Collins and Cox, embrace cognitive relativism but reject moral relativism. ${ }^{18}$ Marxist scholars working in the 'radical science' tradition, such as Young and Cooter, embrace cognitive relativism about science - for them, science is social relations but they have no difficulty in adopting a particular political stance. ${ }^{19}$ Similarly, Donald MacKenzie has outlined the parallels between the Marxist approach to science and technology, and the relativistic work in the sociology of science. ${ }^{20}$ Bijker, Edge, Collins and Shapin have, in various ways, sketched out the implications which relativist science studies may have for science teaching. ${ }^{21}$ Finally, that cognitive relativism does not necessarily entail ontological relativism can be seen from the writings of Collins. ${ }^{22}$ Collins is a relativist about the natural world, but claims to be a realist about the social world. We give these examples merely to demonstrate that our relativist position does not necessarily lead to political neutrality, and that the assumed connection between political neutrality and relativism cannot be used as an easy way to reject our relativist approach towards technology.

Perhaps the more interesting question is just what are the political and policy implications of the new work on technology? It is probably too early to offer much guidance here, but we do want to suggest that there are potential implications for politics and for policy. If Russell wishes to argue that what should be put on the political agenda is the viability of technologies devoted to specific social needs neglected in the dominant capitalist milieu (that is, alternative technologies), then any academic enterprise which 
shows that technologies are integrally shaped by society, and which thereby rejects technological determinism, is perfectly consistent with his goals. Our approach would endeavour to show that any claims that alternative technologies are rejected on purely technical grounds are false. This, of course, is not a new message. David Noble and other labour historians, have been arguing it for many years before the new sociology of technology came along. ${ }^{23}$

Similarly, we would expect that detailed studies of how particular technologies are shaped could be of use to policymakers. For instance, any technology policy would have to be cognizant of such features as: technology is not merely applied science; that the crucial questions concern not so much the social impact of technology but the societal input into technology, particularly at the design stage; that there is choice over technological options; and that a complex of societal factors shape technology, and that by studying these factors in more detail it may be possible to encourage the development of particular types of technology. ${ }^{24}$ To give just a small example: one notion which has proved to be useful in the new sociology of technology has been that of a 'reverse salient'. This idea was first developed by Thomas Hughes, and is drawn from military history. ${ }^{25} \mathrm{~A}$ reverse salient is part of a battlefront which lags behind the rest, and where most attention is devoted. Hughes argues that reverse salients will occur within a technical system, and that they will become the focus of innovative energy as system builders try to correct them. It can be argued that the 'software crisis' of the computer industry in the 1960 s was a classic reverse salient. All the inventive energy for a time was focused upon producing new software, and standardizing software. Clearly, a technology policy informed by such notions might be better equipped to spot reverse salients as they occur, and make interventions in terms of ensuring that resources are available to deal with them.

In summary, we reject Russell's claims that the sociology of science has little relevance to the study of technology. Russell's misconceptions on this point seem to have arisen from a misreading of the sociology of science literature. However, we welcome his general discussion, and we have tried to point to differences in emphasis in his approach, in that of our own, and in other work in the new sociology of technology. We eagerly await the detailed case studies of the development of technology which his approach promises. 
The authors are grateful to Brian Wynne for helpful discussion of the political consequences of the new sociology of technology.

1. S. Russell, 'The Social Construction of Artefacts: A Response to Pinch and Bijker', Social Studies of Science, Vol. 16 (1986), 331-46.

2. R. Laudan (ed.), The Nature of Technological Knowledge: Are Models of Scientific Change Relevant? (Dordrecht: Reidel, 1984); D. MacKenzie and J. Wajcman (eds), The Social Shaping of Technology (Milton Keynes, Bucks.: The Open University Press, 1985).

3. W. E. Bijker, T. P. Hughes and T. J. Pinch (eds), The Social Construction of Technological Systems - New Directions in the Sociology and History of Technology (Cambridge, Mass.: MIT Press, 1986, forthcoming).

4. J. Law, 'International Workshop on New Developments in the Social Studies of Technology', 4S Review, Vol. 2 (Winter 1984), 9-13, esp. 13.

5. See, for example, B. Elzen, 'Two Ultracentrifuges: A Comparative Study of the Social Construction of Artefacts', Social Studies of Science, Vol. 16 (1986); forthcoming.

6. See, for example, T. J. Pinch, 'Towards an Analysis of Scientific Observation: The Externality and Evidential Significance of Observational Reports in Physics', Social Studies of Science,. Vol. 15 (1985), 3-36; B. Latour (ed.), Les Vues de L'Esprit, special issue of Culture Technique (June 1985); and P. Galison, 'Bubble Chambers and the Experimental Workplace', in P. Achinstein and O. Hannaway (eds), Observation, Experiment, and Hypothesis in Modern Physcial Science (Cambridge, Mass.: MIT Press, 1985), 309-73.

7. For an indication of the diversity of types of science, see $\mathbf{R}$. Whitley, The Intellectual and Social Organization of the Sciences (Oxford: Clarendon Press, 1985).

8. M. J. Mulkay, 'Knowledge and Utility: Implications for the Sociology of Knowledge', Social Studies of Science, Vol. 9 (1979), 63-80.

9. See, for example, E. W. Constant, 'Scientific Theory and Technological Testability: Science, Dynamometers, and Water Turbines in the 19th Century', Technology and Culture, Vol. 24 (1983), 183-98; D. MacKenzie, 'Missile Accuracy - A Case Study in the Social Processes of Technological Change', in Bijker et al., op.cit. note 3; MacKenzie, 'From Kwajalein to Armageddon? Testing and the Social Construction of Missile Accuracy', paper presented to the conference on The Uses of Experiment (Bath, UK: University of Bath, Science Studies Centre, 30 August-2 September 1985).

10. For another critique of our use of the evolutionary model, see $\mathbf{H}$. van den Belt and A. Rip, 'The Nelson-Winter/Dosi Model and Synthetic Dye Industry', in Bijker et al., op.cit. note 3 .

11. M. Callon, 'Pour une sociologie des controverses technologiques', Fundamenta Scientiae, Vol. 2 (1981), 381-99; and 'Society in the Making: The Study of Technology as a Tool for Sociological Analysis', in Bijker et al., op.cit. note 3.

12. W. E. Bijker, 'The Social Construction of Bakelite - Towards a Theory of Invention', in Bijker et al., op.cit. note 3.

13. See T. P. Hughes, 'The Evolution of Large Technological Systems', in 
Bijker et al,. op.cit. note 3; J. Law, 'Technology and Heterogeneous Engineering: The Case of the Portuguese Expansion', in Bijker et al., op.cit. note 3; M. Callon (1986), op.cit. note 1; and Hughes, 'The Seamless Web: Technology, Science, Etcetera, Etcetera', Social Studies of Science, Vol. 16 (1986), 281-92.

14. For another approach to dealing with comsumer-based technologies, see R. Schwartz Cowan. 'The Consumption Junction: A Proposal for Research Strategies in the Sociology of Technology', in Bijker et al., op.cit. note 3.

15. See D. MacKenzie, 'The Missile Accuracy System', paper presented to the International Congress of the History of Science (Berkeley, Calif., 31 July - 8 August 1985); MacKenzie draws upon B. Latour, 'Give Me a Laboratory and I Will Raise the World', in K. Knorr-Cetina and M. Mulkay (eds), Science Observed (London: Sage, 1983), 141-70.

16. T. P. Hughes, Networks of Power: Electrification in Western Society, 1880-1930 (Baltimore, Md.: Johns Hopkins University Press, 1983).

17. A position in which social factors and purely technical factors combine is advocated by Steven Kline and Walter Vincenti (personal correspondence).

18. H. M. Collins and H. Cox, 'Recovering Relativity: Did Prophecy Fail?', Social Studies of Science, Vol. 6 (1976), 423-44.

19. B. Young, 'Science is Social Relations', Radical Science Journal, No. 5 (1977), 65-129; R. Cooter, 'Deploying "Pseudoscience": Then and Now', in M. Hansen, M. Order and R. G. Weyant (eds), Science, Pseudoscience and Society (Waterloo, Ontario: Wilfred Laurier Press, 1980), 237-72.

20. D. MacKenzie, 'Marx and the Machine', Technology and Culture, Vol. 25 (1984), 473-502.

21. W. E. Bijker, 'Images of Science: Incorporating the Results of Recent Science Studies in Science Education; An Argument and an Example', paper presented to the conference The Uses of Experiment (Bath, UK: University of Bath, Science Studies Centre, 30 August-2 September 1985); D. O. Edge, 'Dominant Scientific Methodological Views: Alternatives and Their Implications', in D. Gosling and B. Musschenga (eds), Science Education and Ethical Values (Geneva: World Council of Churches Publications, 1985), 1-9; H. M. Collins and S. Shapin, 'Experiment, Science Teaching and the New History and Sociology of Science', paper presented to the International Conference on Using History of Physics in Innovatory Physics Education (Pavia, Italy, 5-9 September 1983), and 'The Historical Role of the Experiment', in F. Bevilacqua and P. J. Kennedy (eds), Using History of Physics in Innovatory Physics Education (Pavia: Centro Studi per la Didattica, Università di Pavia and the International Commission on Physics Education, 1983), 283-92. See also Gerard de Vries' comments in 'Experiments in Bath', EASST Newsletter, Vol. 4, No. 4, (November 1985), 13-17.

22. H. M. Collins, Changing Order: Replication and Induction in Scientific Practice (London: Sage, 1985).

23. See, for example, D. F. Noble, Forces of Production: a Social History of Industrial Automation (New York: Knopf, 1984); S. Melman, Profits Without Production (New York: Knopf, 1983).

24. Some of these issues are addressed by B. Wynne, 'Reflecting the Issues of Risk and Public Acceptance: the Social Viability of Technology'. Futures, Vol. 15 (February 1983), 13-32.

25. Hughes, op.cit. notes 13 and 16. 
Trevor Pinch is a Lecturer in Sociology at the University of York. He has carried out several studies of controversies in science. His current interests are in the sociology of technology and the sociology of economics. He is author of Confronting Nature: The Sociology of Solar-Neutrino Detection (Dordrecht: Reidel) and co-author (with H. M. Collins) of Frames of Meaning (London: Routledge and Kegan Paul). Author's addresses: Trevor Pinch - Department of Sociology, University of York, Heslington, York Y01 5DD, UK; Wiebe Bijker - 'De Boerderij', Twente University of Technology, Postbox 217, 7500 AE Enschede, The Netherlands. 